\title{
IPTEKS BERBASIS INKUBASI INOVASI DAN DUNIA USAHA: MARKET RESEARCH PRODUK-PRODUK INOVASI UNIVERSITAS ANDALAS
}

\author{
Berri Brilliant Albar *), Indah Maya Sari, Mayang Larasati, dan Sapta Eka Putra \\ Fakultas Ekonomi Universitas Andalas \\ *) Email: berribrilliantalbar@eb.unand.ac.id
}

\begin{abstract}
ABSTRAK
Produk-produk inovasi Universitas Andalas memasuki tahap selanjutnya dalam rangkaian proses pengembangan produk menuju komersialisasi. Sebagai produk pada masa perkembangan perlu dilakukan market research untuk mengetahui preferensi dan persepsi konsumen, untuk menjadi dasar analisis bisnis dan perbaikan. Untuk itu perlu dilakukan kegiatan pengabdian untuk membantu para inventor, pengembang, dan mitra dalam meneliti pasar dan mengetahui preferensi calon konsumennya sebagai salah satu program Ipteks berbasis Inkubasi Inovasi dan Dunia Usaha (IbIIDU). Kegiatan ini dilakukan melalui deep interview dengan inventor, uji produk/sampel dan simulasi, survey dan observasi pada pasar dan segmentasinya. Teknik riset pasar digunakan dengan cara mencari, mengumpulkan, dan menganalisis informasi tentang konsumen atau pasar yang sesuai dengan usaha yang mereka jalankan. Selain kualitas produk melalui pemahaman kebutuhan dan selera konsumen, hal lain yang juga membangun penilaian konsumen terhadap produk adalah persepsi. Positioning merupakan analisis awal untuk membangun persepsi di benak konsumen. Kegiatan ini bertujuan untuk memperoleh dokumen riset pasar untuk mengetahui persepsi konsumen mengenai produk-produk inovasi setelah mengkonsumsi produk tersebut sehingga dapat dijadikan acuan untuk perbaikan produk sebelum dikomersialisasikan. Kegiatan ini juga bertujuan membantu untuk menganalisis positioning dan merancang strategi pemasaran untuk tahap selanjutnya. Memahami kebutuhan konsumen dan menciptakan produk yang mampu memenuhi kebutuhan dan menyelesaikan masalah konsumen adalah kunci suksesnya komersialisasi produk. Kegiatan ini melakukan riset pasar pada 7 produk inovasi Universitas Andalas pada bidang food and beverage dan melibatkan 100 responden untuk masing-masing produknya yang tersebar di wilayah Sumatera Barat. Kegiatan ini berhasil menghasilkan dokumen riset pasar per produk, hasil analisis positioning, dan rencana strategi pemasaran yang dapat digunakan oleh setiap inventor dan pengembang masing-masing produk untuk melakukan pengembangan dan komersialisasi produknya.
\end{abstract}

Kata Kunci: inovasi, riset pasar, persepsi

\section{IPTEKS-based on Incubation Innovation and Business World: Market Research of Universitas Andalas's Innovation Products}

\begin{abstract}
Universitas Andalas innovative products enter the next stage in the series of product development processes leading to commercialization. As a product in the period of development, market research needs to be done to determine consumer preferences and perceptions, to be the basis of business analysis and improvement. For this reason, community service activities are needed to help inventors, developers and partners in researching the market and knowing the preferences of prospective customers as one of the Innovation and Business-based Science and Technology (IbIIDU) incubation programs. This activity is carried out through deep interviews with inventors, product / sample tests and simulations, surveys and observations on the market and its segmentation. Market research techniques are used by searching, gathering, and analysing information about consumers or markets that are appropriate for the business they run. In addition to product quality through understanding the needs and tastes of consumers, another thing that also builds consumer ratings of products is perception. Positioning is the initial analysis to build perception in the minds of consumers. This activity aims to obtain market research
\end{abstract}


Website. http://hilirisasi.lppm.unand.ac.id e-ISSN: 2621-7198

documents to determine consumer perceptions about innovation products after consuming the product so that it can be used as a reference for product improvement before commercialization. This activity also aims to help to analyse positioning and design marketing strategies for the next stage. Understanding consumer needs and creating products that are able to meet the needs and solve consumer problems are the keys to successful product commercialization. This activity carried out market research on 7 Andalas University innovation products on food and beverage category with 100 respondents for each of their products spread across the West Sumatra region. This activity produces product market research documents that can be used by each inventor and developer of each product to develop and commercialize their products.

Keywords: innovation, market research, perception

\section{PENDAHULUAN}

Pemasaran modern adalah pemasaran yang berorientasi pada konsumen. Konsumen merupakan dasar utama dalam perencanaan dan pengembangan produk baru. Memahami kebutuhan konsumen dan menciptakan produk yang mampu memenuhi kebutuhan dan menyelesaikan masalah konsumen adalah kunci suksesnya komersialisasi produk. Oleh karenanya diperlukan Manajemen pemasaran yang lebih kompleks, salah satunya dengan riset pasar. Riset pasar dalam memulai suatu bisnis diperlukan sebelum melakukan komersialisasi. Teknik riset pasar digunakan oleh calon pengusaha maupun pengusaha yang telah berjalan supaya bisnisnya lebih berkembang dengan cara mencari, mengumpulkan, dan menganalisis informasi tentang konsumen atau pasar yang sesuai dengan usaha yang mereka jalankan.

Selain kualitas produk melalui pemahaman kebutuhan dan selera konsumen, hal lain yang juga membangun penilaian konsumen terhadap produk adalah persepsi. Positioning merupakan analisis awal untuk membangun persepsi di benak konsumen. Positioning adalah dasar untuk merancang produk dan bauran pemasaran agar dapat tercipta kesan tertentu di ingatan konsumen. Sehingga, konsumen memahami dan menghargai apa yang dilakukan perusahaan dalam membangun value produknya.

Melalui program Ipteks berbasis Inkubasi Inovasi dan Dunia Usaha (IbIIDU) sejak tahun 2016 hingga 2018 telah dihasilkan 19 produk yang tergolong dalam produk improvements dan modifications. Produk tersebut merupakan perbaikan dari produkproduk yang telah ada dan penambahan manfaat-manfaat baru. Pengembangan produk baru dapat dilakukan melalui delapan tahap (Kotler dan Keller, 2016). Riset pasar merupakan tahap ke-7 dalam rangkaian alur pengembangan produk baru.

Pengembangan produk baru merupakan kegiatan yang dimulai dengan penemuan dan pencarian ide, selanjutnya dilakukan screening pada ide-ide yang tersedia. Ide yang disetujui selanjutnya diteruskan dalam pengembangan konsep dan uji awal produk yang dapat menimbulkan keinginan konsumen untuk mencobanya. Selanjutnya dilakukan proses pengembangan strategi pemasaran, yang meliputi rencana pemasaran sasaran dan bauran pemasaran. Proses selanjutnya adalah analisis bisnis untuk mengetahui target keuntungan dan tujuan. Setelah analisis bisnis cukup memenuhi perhitungan keuntungan, produk dilanjutkan pada tahap pengembangan akhir dan siap untuk diujikan pada konsumen. Tahap menguji kepada konsumen inilah yang dilakukan dalam bentuk riset pasar pada program IbIIDU ini. Tahap ini 
merupakan tahap akhir untuk menakar apakah produk ini selanjutnya dapat dikomersilkan sebagai produk baru.

Ini adalah kegiatan awal inkubasi dalam bidang pemasaran. Sosialisasi inkubator dan produk-produk tenant inkubator bisa menjadi tonggak bagi kelanjutan dan keberlangsungan komersialisasi produk di masa yang akan datang. Kegiatan ini bertujuan untuk mengetahui persepsi konsumen mengenai produk-produk inovasi setelah mengkonsumsi produk tersebut sehingga dapat dijadikan acuan untuk perbaikan produk sebelum dikomersialisasikan.

Melalui program Ipteks berbasis Inkubasi Inovasi dan Dunia Usaha (IbIIDU): Market Research Produk-Produk Inovasi Universitas Andalas diharapkan dapat tercapai tujuan-tujuan berikut:

1. Diperolehnya dokumen riset pasar dari masing-masing produk yang memuat penilaian dan preferensi dari konsumen.

2. Mengetahui positioning produk-produk melalui point of parity (POP) dan point of difference (POD).

3. Memberikan saran perbaikan dan pengembangan produk-produk sebelum dikomersialisasikan.

\section{METODE}

Metode pelaksanaan kegiatan ini untuk mendapatkan dokumen riset pasar pada produk-produk dilakukan dengan wawancara, uji produk, kuisioner, survey, dan observasi. Ini dilakukan dengan menggunakan langkah-langkah sebagai berikut:

Tabel 1. Metode Pelaksanaan Kegiatan

\begin{tabular}{|c|c|c|}
\hline No. & Metode Pelaksanaan & Kegiatan \\
\hline 1. & $\begin{array}{l}\text { Wawancara/ } \\
\text { deep interview }\end{array}$ & $\begin{array}{l}\text { Wawancara dilakukan secara langsung dengan tatap muka dengan } \\
\text { inventor produk yang telah dipilih untuk tujuh produk berikut: } \\
\text { a. Cookies kopi Hazagi (inventor Dr. Donard Games) } \\
\text { b. Cookies Sorgume (inventor Dr. Eka Candra Lina) } \\
\text { c. Crackers murbei Buibu (inventor Prof. Kesuma Sayuti) } \\
\text { d. Frozen Yoghurt Takicok (Inventor Dr. Aronal) } \\
\text { e. Kopi kulit manggis Idola (inventor Prof. Akmal Djamaan) } \\
\text { f. Teh kulit manggis Idola (inventor Prof. Akmal Djamaan) } \\
\text { g. Teh gambir Unca (inventor Prof. Dr. Deddi Prima Putera) } \\
\text { Wawancara juga dilakukan secara langsung kepada calon konsumen } \\
\text { di lokasi riset pasar. }\end{array}$ \\
\hline 2. & $\begin{array}{l}\text { Uji produk/ } \\
\text { sampel dan simulasi }\end{array}$ & $\begin{array}{l}\text { Produk disajikan dalam kondisi penyajian yang sesuai (diseduh } \\
\text { panas, dingin, dalam suhu kamar, kering, dan lainnya) dan diberikan } \\
\text { kepada calon konsumen agar dapat dicoba dan diberikan penilaian. }\end{array}$ \\
\hline 3. & Kuesioner & $\begin{array}{l}\text { Kuisioner diberikan secara langsung yang berisi pertanyaan kepada } \\
\text { calon konsumen (yang telah mencoba produk) mengenai merek, rasa, } \\
\text { kemasan, harga, preferensi pembelian, kekurangan serta kelebihan } \\
\text { produk. Calon konsumen akan diberi imbalan berupa souvenir atau } \\
\text { produk secara gratis. }\end{array}$ \\
\hline 4. & Survey & $\begin{array}{l}\text { Dilakukan lebih menyeluruh dengan sampel } 100 \text { calon konsumen per } \\
\text { produk sehingga dapat lebih mewakili demografi secara keseluruhan. }\end{array}$ \\
\hline 5. & Observasi & Melakukan pengamatan secara langsung kondisi yang ada di pasar. \\
\hline
\end{tabular}


Kegiatan pengabdian ini dilaksanakan mulai 1 November hingga 29 Desember 2019, dengan tahapan sebagai berikut :

Tabel 2. Jadwal Kegiatan

\begin{tabular}{|c|c|c|c|}
\hline No. & Jadwal & Kegiatan & Kendala \\
\hline 1. & 1-10 November 2019 & $\begin{array}{l}\text { Penetapan objek produk: } \\
\text { analisis data produk-produk } \\
\text { inovasi Unand }\end{array}$ & $\begin{array}{l}\text { Kesulitan menghubungi } \\
\text { inventor, tidak ada respon dari } \\
\text { beberapa inventor }\end{array}$ \\
\hline 2. & 11-13 November 2019 & $\begin{array}{l}\text { Mengagendakan jadwal } \\
\text { wawancara dengan inventor }\end{array}$ & $\begin{array}{l}\text { Kesulitan mengagendakan } \\
\text { jadwal karena kesibukan } \\
\text { inventor }\end{array}$ \\
\hline 3. & 14-29 November 2019 & $\begin{array}{l}\text { Wawancara/deep interview } \\
\text { dengan inventor dan tenant }\end{array}$ & \\
\hline 4. & 15-25 November 2019 & Produksi produk & Waktu tunggu \\
\hline 5. & 24 November 2019 & $\begin{array}{l}\text { Presentasi di Konferensi } \\
\text { Nasional Klaster dan } \\
\text { Hilirisasi Riset Berkelanjutan } \\
\text { (KN-KHRB) V } 2019\end{array}$ & \\
\hline 6. & 25-28 November 2019 & Persiapan riset pasar & $\begin{array}{l}\text { Peralatan untuk penyajian } \\
\text { produk yang beragam }\end{array}$ \\
\hline 7. & $\begin{array}{l}28 \text { November - } 5 \text { Desember } \\
2019\end{array}$ & $\begin{array}{l}\text { Riset Pasar di Padang dan } \\
\text { Bukittinggi }\end{array}$ & $\begin{array}{l}\text { Kesulitan mencari responden } \\
\text { yang bersedia meluangkan } \\
\text { waktu untuk mencoba produk } \\
\text { baru }\end{array}$ \\
\hline 8. & 6-12 Desember 2019 & Input dan analisis data & \\
\hline 9. & 13 Desember 2019 & $\begin{array}{l}\text { Dokumen riset selesai untuk } \\
\text { selanjutnya diserahkan } \\
\text { kepada inventor }\end{array}$ & \\
\hline 10. & 29 Desember 2019 & $\begin{array}{l}\text { Publikasi di Harian Padang } \\
\text { Ekspres halaman } 17\end{array}$ & \\
\hline 11. & 28-29 Desember 2019 & $\begin{array}{l}\text { Penyusunan laporan akhir } \\
\text { kegiatan }\end{array}$ & \\
\hline
\end{tabular}

Untuk mengetahui positioning produk-produk melalui point of parity (POP) dan point of difference (POD) dilakukan dengan menganalisis hasil tabulasi data pada unsur-unsur umum produk dan unsur-unsur khusus yang menjadi pembeda produk. POP dan POD di takar berdasarkan respons konsumen saat dilakukan riset pasar. Selanjutnya hasil analisis preferensi konsumen dan positioning produk di benak konsumen, dilakukan penyusunan rencana strategi dalam bentuk saran perbaikan dan pengembangan produk-produk sebelum dikomersialisasikan. 


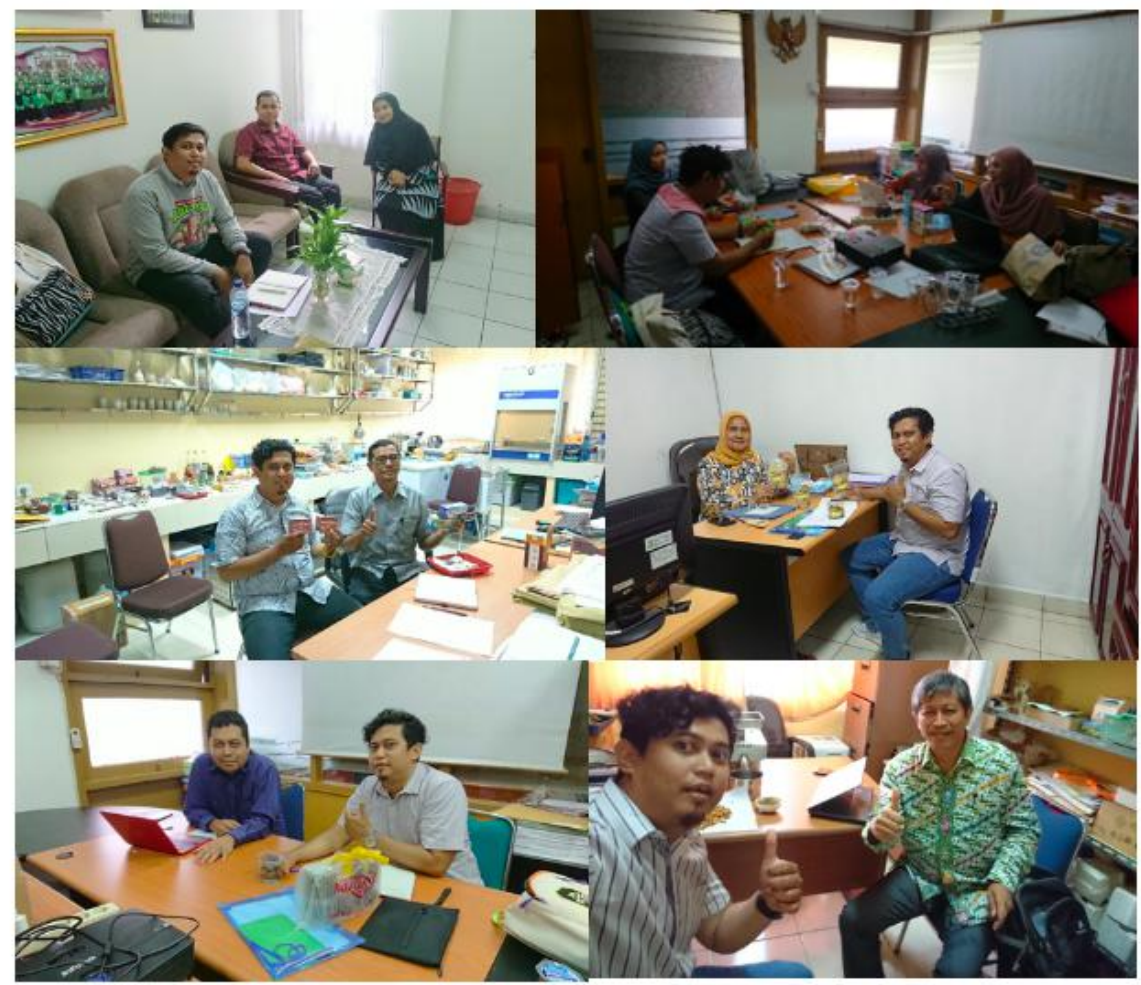

Gambar 1. Kegiatan Deep Interview dengan Inventor

\section{HASIL DAN PEMBAHASAN}

Kegiatan ini dilaksanakan dalam 10 hari pada 1-10 November 2019. Produk yang dipilih merupakan produk-produk inovasi Universitas Andalas, melalui program IBIIDU dari tahun 2016 hingga 2018 tercatat 19 produk. Selanjutnya dikeruncutkan dalam kategori food and baverage. Hal ini dilakukan karena durasi riset pasar yang cukup singkat, sehingga tidak memungkinkan untuk melakukan pengujian pada produk-produk yang berdampak panjang, seperti produk pertanian dan obat-obatan, selain itu faktor keamanan dan etika juga menjadi pertimbangan dalam memilih produk yang akan diujikan kepada calon konsumen. Dalam penelusuran lebih lanjut mengenai ketersediaan produk, akhirnya ditetapkan produk berikut sebagai objek riset pasar:

a. Cookies kopi merek "Hazagi" (inventor Dr. Donard Games)

b. Cookies berbahan sorgum merek "Sorgume" (inventor Dr. Eka Candra Lina)

c. Crackers dari daun murbei merek "Buibu" (inventor Prof. Kesuma Sayuti)

d. Frozen Yoghurt dengan varian original, mangga, dan buah naga merek "Takicok" (Inventor Dr. Aronal)

e. Kopi dengan kulit manggis merek "Idola" (inventor Prof. Akmal Djamaan)

f. Teh dengan kulit manggis merek "Idola" (inventor Prof. Akmal Djamaan)

g. Teh daun gambir merek "Unca" (inventor Prof. Deddi Prima Putera)

Persiapan riset pasar meliputi pemilihan lokasi, penyajian dan pembagian produk, persiapan kuisioner, dan peralatan pendukung lainnya. Kegiatan ini 
dilaksanakan pada tanggal 25-28 November. Lokasi yang dipilih yaitu di Kota Padang dan Kota Bukittinggi. Kota Padang sebagai ibu kota Provinsi Sumatera Barat dilaksanakan di Kecamatan Padang Utara, dimana di daerah ini terdapat sarana olahraga dan pendidikan sebagai pusat keramaian. Kota Bukittinggi sebagai salah satu pusat perdagangan dilaksanakan di Kecamatan Aua Birugo Tigo Baleh. Persiapan selanjutnya meliputi penyediaan termos 3 liter untuk menyeduh teh dan kopi, penyediaan box pendingin untuk yoghurt, 400 gelas plastik, 300 piring kertas untuk cookies dan crackers, meja dan baki. Untuk calon konsumen yang menjadi responden juga diberikan souvenir berupa alat tulis.

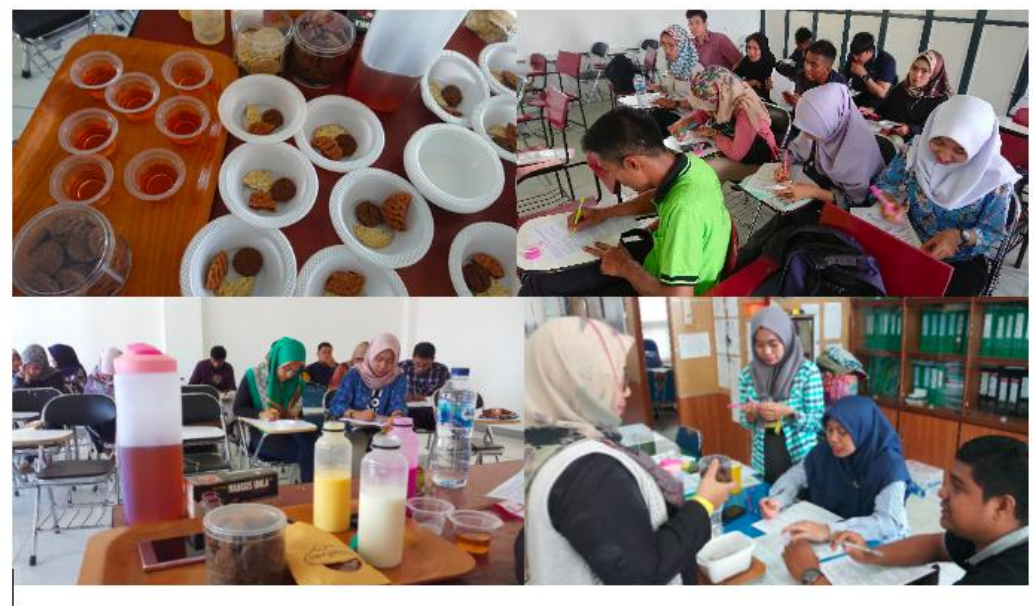

Gambar 2. Kegiatan Riset Pasar

Riset pasar dilakukan pada tanggal 28 November - 5 Desember 2019. Awalnya riset dilakukan pada pusat keramaian, namun dirasa kurang efektif karena sedikitnya masyarakat yang mau meluangkan waktu untuk mencoba produk-produk sampel. Akhirnya riset dilakukan dengan mengunjungi perumahan dan lembaga pendidikan di daerah-daerah yang telah ditentukan dengan tetap memperhatikan sebaran demografi dari responden. Responden menyicipi produk untuk selanjutnya dinilai dan diisikan ke dalam kuisioner yang telah disediakan. Sembari mengisi kuisioner, juga dilakukan wawancara pada beberapa responden.

Kuisioner yang telah diisi oleh responden selanjutnya di input dan dianalisis pada tanggal 6-12 Desember 2019 dengan mengacu pada pembagian demografi:

a. Usia 18-30 tahun (pemuda), dan lebih dari 30 tahun (dewasa)

b. Penghasilan yang merujuk pada kelas sosial: uang jajan, dibawah Rp. 3.750.000 (kelas bawah), diatas Rp. 3.750.000 (kelas menengah dan atas)

c. Daerah geografis panas (Kota Padang) dan sejuk (Bukittinggi)

d. Jenis pekerjaan

e. Jenis kelamin: laki-laki dan perempuan

Selain itu juga diajukan pertanyaan yang mengacu pada penilaian setelah mengkonsumsi produk-produk tersebut, seperti:

a. Pertanyaan essay tentang pendapat mengenai merek produk

b. Tampilan dan kualitas kemasan: Sangat tidak bagus hingga Sangat Bagus (skala Likert) 
c. Harga : Murah, Sesuai, atau Mahal

d. Rasa : Sangat tidak enak hingga Sangat Enak (skala Likert)

e. Minat untuk membeli : Ya atau Tidak

f. Pertanyaan essay mengenai kelebihan, kekurangan, dan saran.

Hasil pengisian kuisioner selanjutnya diolah dan dianalisis sehingga dapat menghasilkan beberapa penilaian dan saran perbaikan terhadap masing-masing produk. Melalui analisis juga dapat dihasilkan posisitioning yang sesuai bagi produk-produk tersebut. Hasil riset pasar mengenai masing-masing produk inovasi tersebut selanjutnya diserahkan kepada setiap inventor dalam bentuk dokumen riset yang selanjutnya dapat digunakan sebagai acuan untuk perbaikan, pengembangan, dan komersialisasi produk..

\section{KESIMPULAN DAN SARAN}

Kegiatan ini berhasil merangkum persepsi konsumen dari berbagai segmentasi pasar terhadap produk-produk inovasi Universitas Andalas yang menjadi sampel. Melalui kegiatan ini diperoleh point of parity dan point of difference dari produk tersebut, Calon konsumen memberikan penilaian positif dari segi rasa dan minat beli. Kegiatan ini juga membantu memperkenalkan dan mengedukasi calon konsumen tentang produk-produk ini, yang diharapkan dapat menjadi pembeli ketika dikomersialisasikan. Dokumen riset pasar diserahkan kepada masing-masing inventor dan mitra terkait dalam bentuk dokumen tertutup. Dokumen ini memuat hasil uji coba produk pada konsumen, penilaian konsumen, preferensi konsumen, saran dan usulan perbaikan dari konsumen, selain itu juga memuat hasil analisis positioning produk terkait, serta saran dan analisis dari peneliti untuk perbaikan dan pengembangan produk serta rencana strategi pemasaran. Dokumen riset pasar ini diharapkan dapat dijadikan acuan untuk perbaikan, pengembangan, dan komersialisasi produk ke depannya.

\section{UCAPAN TERIMAKASIH}

Ucapan terima kasih disampaikan kepada Lembaga Penelitian dan Pengabdian kepada Masyarakat Universitas Andalas, Science Techno Park Universitas Andalas, dan Inkubasi Bisnis Teknologi Universitas Andalas. Terima kasih atas kerjasama dari seluruh inventor produk-produk inovasi Universitas Andalas: Dr. Donard Games, Dr. Eka Candra Lina, Prof. Kesuma Sayuti, Dr. Aronal, Prof. Akmal Djamaan, Prof. Akmal Djamaan, dan Prof. Dr. Deddi Prima Putera semoga bermanfaat. Terima kasih untuk segenap masyarakat yang bersedia meluangkan waktunya untuk menjadi sampel pada riset pasar ini.

\section{DAFTAR PUSTAKA}

Games, D. 2019. Upaya membangun kemandirian ekonomi penyandang disabilitas di Sumatera Barat. Jurnal Hilirisasi IPTEKS 2 (4.a) 415-422. 
Griffin, R.W. and Pustay, M.W. 2014. International Business: A Managerial Perspective $8^{\text {th }}$ edition. Pearson

Kartajaya, H. 2011. Hermawan Kartajaya on Marketing. Gramedia, Jakarta

Kotler, P. and Keler, K.L. 2016. Marketing Management $15^{\text {th }}$ edition. Pearson Prentice Hall, New Jersey

Kotler, P and Amstrong, G. 2018. Principles of Marketing, 17 $7^{\text {th }}$ edition, International Edition, Prentice Hall, New Jersey

Maholtra, N. and Birks, D. 2007. Marketing Research: An Applied Orientation $3^{\text {rd }}$ edition, Pearson Education

Ferdian, R. 2019. Digital Marketing untuk Produk Unggulan Nagari Bukik Batabuah Kabupaten Agam. Jurnal Hilirisasi IPTEKS. 2 (4.b) 500-508

Sari, D. K., Games, D. 2019. Repositioning karya persatuan penyandang disabilitas Indonesia (PPDI) Kota Padang dengan Strategi IMC dan Standarisasi Produk. Jurnal Warta Pengabdian Andalas, 26 (4.b).

Schiffman, L. and Kanuk, L. 2015. Consumer Behavior $11^{\text {th }}$ edition, Global Edition. Pearson

Trout, P. 2005. Innovation Management and New Product Development, Pearson Education Limited

Vahlia, I. 2019. Pelatihan E-comerce dan manajemen keuangan pada keripik pisang arjuna. Jurnal Hilirisasi IPTEKS. 2 (4.b) 